\title{
Increase the organization's crisis prevention costs and enhance the image of the organization
}

\author{
Xue Lei ${ }^{1, a}$, Yinlin Wang ${ }^{2, b}$ \\ ${ }^{1}$ Huanggang vocational and technical college , Hubei 438002, China; \\ ${ }^{2}$ Huanggang vocational and technical college, Hubei 438002, China. \\ a3053903721@qq.com, b80916420@qq.com
}

Keywords: Component, Formatting, organization; crisis; cost of prevention; organization image

\begin{abstract}
This template explains and demonstrates how to prepare your camera-ready manuscript for publisher. The best is to read these instructions and follow the outline of this text. Please make the page settings of your word processor to A4 format ( $21 \times 29,7 \mathrm{~cm}$ or 8 x 11 inches); with the margins: bottom $1.5 \mathrm{~cm}$ (0.59 in) and top $2.5 \mathrm{~cm}$ (0.98 in), right/left margins must be $2 \mathrm{~cm}$ (0.78 in). Your manuscript will be reduced by approximately $20 \%$ by the publisher. Please keep this in mind when designing your figures and tables etc. Abstract: This paper aims to enhance the image of social organization, Through the analysis of the relevant knowledge of the crisis, the existing problems are studied, and the measures to deal with the crisis are put forward. We do these research to increase the organization's crisis prevention costs in order to reduce the harm and loss, to realize the high cost of social organization and high efficiency.
\end{abstract}

\section{Necessity to enhance the image of social organization.}

In the theory of public relations, the social organization is collective activities which could work in cooperation with a due division of labour. It have a planned and conscious realization of a specific goal, such as a country, an enterprise, a community, etc. Social organization has the characteristics of purpose, integrity, relevance, dynamic, openness, adaptability, multi function and internal factors. Parsons, a representative of the western structure and function, divides the social organizations into four categories: Organization of economic production, political organization, coordination of organizations and educational organizations. In order to realize the social organization in a certain period of time the cost of the minimum, the desire to maximize the desire, it requires social organizations have a conscious awareness of the public relations. Awareness of public relations is the public relations theory and principles of public relations internalization of self-cultivation and behavior norms. It includes to set a good image of the organization awareness, public awareness, consciousness of sincere mutual benefit, long-term awareness, communication communication consciousness, innovative consciousness and high degree of legal awareness.

The core goal of public relations is to improve the image of social organizations in the public mind, improve the organization of the visibility, reputation, harmony, let the public understand the organization, acceptance, trust and support, to indirectly realize the goal of profit or management. A social organization can accomplish this by putting in a lot of people's financial power and a certain medium, such as a product. In the eyes of the public on an organization's overall view, a comprehensive evaluation is the image of the organization. It has the characteristics of subjectivity, relative stability, objectivity, variability, uniqueness and integrity. Shaping the image of the organization has the following significance: the organization's internal cohesion and integration of the function, is the development of the organization of the spiritual resources; on the outside of the organization to attract the public and the expansion of the market function, is an important economic resources; This is the Organization's survival and Development Foundation. The image of the 
organization is a kind of intangible assets. The British scholar Charles. Handy estimation: a unit value of intellectual asset is three to four times its book value. Therefore, enhancing the social organizations in the public mind the image it is necessary.

\section{The establish of a correct sense of crisis management}

The organization's desire to achieve will encounter different obstacles. In particular, the impact of political, economic, environmental, climate, natural, human factors and other factors, the emergence of a variety of crises is inevitable. As people know your birthday, don't know to go the same day, not pluvial stiff Miao, in order to reduce future disputes, some young people just heritage allocation scheme to protect the interests of the people he wanted to protect the profit. Despite the increase in the cost of prevention in the justice, but he needs to protect the interests of security, to achieve the purposes, peace of mind and heart wide, but also reduce the lawsuit trouble for the society. This is the same reason to achieve the organization's desire the organization to manage the crisis, the danger for the opportunity, this is the dialectical point of view of philosophy.

Crisis management is refers to the people to organize their own conditions and external environment, analysis and prediction of possible crisis, formulate effective measures, when a crisis occurs, can effectively resolve the crisis and to restore the reputation in the market and a set of mechanisms. In 1997 by the joint response of < property > magazine out of Global 1000 companies survey found that the possibility of the potential crisis from high to low order has: work in violence, kidnappings, terrorist activities, fraud, damage to the product and claim, moral norms, chief executive officer of the successor and replacement and so on. In the commercial activities, the crisis management is a measure of the importance of a chief executive influence. Based on the crisis is an inevitable phenomenon, they'll with correct sense of crisis management to establish a preventive system, to maximize the reduce the likelihood of crisis and reduce casualties and property losses. Some of the crisis is to belong to not resistance (such as earthquakes, floods, the spread of the virus, etc.) or outsiders vandalism (such as bombings) on 2.2016 in April, the Shanghai Nanjing high-speed on 56 cars car crashing by 3 dead 21 people were trapped, etc., should be to improve the driver's life first, risk awareness. Such accidents can not be in advance to prevent the accident, which is to use statistical analysis, big data, cloud computing, information processing, psychology, monitoring tools and knowledge to predict, will harm the eradication in the bud. Analyze the causes of the crisis and take measures to prevent the crisis. This is one of the important functions of the organization and management, and it is very important to the sustainable development of the organization.

The organization may be threatened by a variety of crises at any moment, Such as Nanjing, China Health crown round "black moon cake incident"; the United States Johnson \& Johnson "Tylenol capsules mixed with toxic event"; in 2015 deutsche bank losses 68 billion euros. Life in the disputes between doctors and patients, the Chinese do not understand the medical knowledge of the people eating the wrong medicine and die each year about 20 million people; labor dispute; credibility crisis; domestic large animals of endangering public security, in the unknown time may bite people; harmonious family is apart of a third party is not condemned, and third party to raise children there are laws to protect their legitimate interests actually indirectly protect the illegal marriage, so that the three rampant. Third party with snatch the possession of the family of the normal family labor results, and the husband and wife, let the next generation people don't know is non concept and sense of shame. Pornography is rape, robbery, violence, unearned root; intensive mahjong shop, some will be mahjong shop set within the family, crime is more subtle. Multiple partners led to an increase in the incidence of AIDS, bringing a series of social family shocks; dangerous chemicals have not been strictly controlled. Endangered species were sold; the accident Hangzhou 82 year old elderly people living alone at home for several days, and was found late. Genetically modified foods, waste oil, pesticide residues, the use of plastic products, such as long-term harm to people's body, increase the risk of cancer, leading to the increase in the number of people can not be pregnant, the impact of social stability, family harmony. Is more poverty and raising children, Sichuan a desperately poor families have 11 children and inability to cultivate the phenomenon still exist; decades rural fertility 
policy inconsistencies, so that rural family burden, patriarchal ideology, resulting in the divorce rate is rising, the quality of the whole nation has a downward trend. Too many OEM production organization, to let foreigners take about $90 \%$ of the profits, leaving less than $10 \%$ of the profits and a lot of garbage, the cost of pollution control is much higher than $10 \%$ of the profits. Countries should reduce this kind of organization, reduce the discharge of "three wastes" and for future generations to leave the mountains, blue sky and white clouds. Because deception and people's ignorance makes Africa Congo to "children of the witch," the family of disability and death, cheats to obtain property and so on.

The political crisis such as the outbreak of the crisis in Syria in March 2011, in the beginning, people held a peaceful anti-government demonstrations. Soon after, anti-government protests evolved into a full civil war. The United Nations estimates, the civil war in Syria so far has killed 250 thousand people, 11 million people from their homes, the main causes of the refugee crisis. And become Europe no place to hide. The refugees in the international community who will bear the responsibility, who caused the crisis, who are the beneficiaries, whether there is a crisis plan? In view of this, we should do a good job of crisis warning: in all China Chinese border, coastal fortification zone, in order to avoid foreign invaders deliberately provocative, the maintenance of our border its territorial waters sovereignty. Chinese airspace to remember others gave us pain, remember how others Macao is occupied, the Summer Palace was burned who snatch? Chinese ancestors of ceramic calligraphy and painting, among other things, why still other national museum? People by years of suffering, not allow others to commit the same crimes. Some organizations for their own interests bullying poor and small organizations, alienating the neighborhood relations, benefit from fish Weng. Because these organizations for many years to get the sweetness, in war or man-made disaster, the Yellow Crane Tower see capsize, proudly laugh others stupid. Those poor and small organizations, should do a good job in the neighborhood relations, unity unanimously, open their own "ship", punish shipwreck and capsized, don't be used also help with some cash.

\section{Follow the principles of crisis management, and put forward the corresponding measures.}

To deal with the crisis, management of crisis, I must follow in order to provide as soon as possible; to provide; provide all the information, grasp the initiative, do not give the hearsay spreading opportunity. With enthusiasm, initiative, timeliness, calm, authenticity, accountability, rehabilitation and flexibility the principle of dealing with scientific, positive and effective way to win public trust and forgiveness, as soon as possible to restore the organization's reputation and image. Crisis management measures are: pay attention to the fact that the investigation in a timely manner, properly handle the aftermath, different measures were taken according to the different public object, reconstruction of organizational image. Timely report to the higher authorities, in strict accordance with the unified caliber released information, report the situation. So the internal organization of the staff aware of. The accurate and timely events Truth and to take countermeasures inform employees, to work together, to tide over the crisis. The victims dare to assume responsibility, sincerely apologize or compensate for the losses. Calmly and listen to the victim's opinion, attention to victims. Sympathy and comfort the victim, to avoid words and deeds for self defense. To gain the cooperation of the press. Organization to the press to provide facts and relevant information, with a sincere attitude, the press understanding, cooperation and support. Timely release news of stability in the hearts of the people, guide and control the situation of public opinion and comment not blindly, in time for the cooperation of the press.

\section{Establish a good defense system, increase the organization's crisis prevention costs}

When a crisis, to reduce the loss and restore the image. The establishment of a crisis management team with the participation of experts, the establishment of prevention system of crisis situation to do a comprehensive analysis including the causes, casualties, development status and trend, affected by the public and the degree, then work out the corresponding countermeasure quickly. The reaction, 
seize the initiative, actively communicate effectively manage the information in and out. The best method of crisis management is crisis communication. This organization must grasp the initiative report, to tell the truth, quickly said, "timely disclosure of accurate information, to avoid the media hype. Through authoritative opinions, in order to win the public trust. Do remedial work to restore the reputation. Especially the emergence of major accidents, the organization should take responsibility, give the public a compensation for the material and spiritual compensation.

Increase the cost of crisis prevention in August.2007 of the people's Republic of China Emergency Response Law ", from the legal prevention mechanism is established, will be included in the national development of public security standardization work, to avoid the development, people do not follow the rules mining. Prevention first, adhere to the principle of humanitarianism, maintenance organization strengthen the reputation, reputation management, restore the existing losses, to avoid the emergence of new crisis. The public diplomacy and the" going out "strategy, strengthen communication and cooperation with international non-governmental organizations and non-governmental organizations. Our study will occur in countries with trade laws, customs and practices, shaping the image the use of public relations management, promotion of culture and values, the value of the service concept, product demand and value concept of unity, promote products, services of the added value of the products, increase The premium increase. The national emergency treatment mechanism, set up a rescue team organized emergency command system; system security; disaster prevention system; early warning and monitoring system. Perfect service facilities and low-cost rescue services, the establishment of life channel, a helicopter, emergency vehicles, ships, advanced communication facilities, the establishment of public infrastructure, such as breastfeeding, underground drainage system, toilet, earthquake disaster experience and labor protection facilities; return to the society staff working life guidance, again crime; installation of Rural Street camera, soil and water conservation in the Tibetan Plateau, prevent overgrazing; damage, vulnerable groups of trafficking, abandoned children and women, rape young girls under the age of 14 crimes punishable by heavy fines, increase the cost of crime and punishment, make people stop.

The media reported a greater contribution to society of scientists, technology workers reported negative deeds, less injury, social customs, customs news, positive guidance of the next generation is to set up the correct world outlook, outlook, outlook on money, love, family values, education idea -the first adult, after the success of. Build self-confidence, not to score on the hero, there should be a virtue first, no virtue without foundation. Disease screening at the mother with children to strengthen, in the form of legal provisions: eliminate the major diseases of the birth of a child, reduce social not bear the burden. The introduction of competition mechanism, increase the robot, reduce personnel the operation risk of the rescue project; health and popularization of scientific knowledge, reduce the incidence of chronic diseases, in order to maximize the overall interests of the people and countries as the principle, draw lessons from other successful experiences, strengthen international cooperation and information communication, prevention and emergency machine System combination, reduce the occurrence of disasters, build a harmonious society, improve the people's happiness index, reduce stress, create a good image of the organization.

\section{References}

[1] Lei X, Dong Y, Wang Y L. The project of public relations. Nanjing University Press, 2013.8.

[2] Zeng W. Discussion on public relations management and image maintenance of enterprises . 20 15.1 . 